\title{
On the use of factorial experiments for optimizing inhibition effect of acid extract of Gnetum Africana on copper corrosion
}

\author{
A.J. Saka, ${ }^{1}$ * O.N. Ahmed ${ }^{1}$ and A.S. Adekunle ${ }^{2}$ \\ ${ }^{1}$ Department of Mathematics, Obafemi Awolowo University, Ile-Ife, Nigeria \\ ${ }^{2}$ Department of Chemistry, Obafemi Awolowo University, Ile-Ife, Nigeria \\ *E-mail: sakajamiu@gmail.com
}

\begin{abstract}
The inhibition of copper corrosion by acid extract of Gnetum Africana using weight loss method under various independent variables of time, inhibitor concentration and temperature was studied. The data used was retrieved from a three-level factorial experiment by Nkuzinna et al. (2014) and reanalyzed. The re-analysis was necessary to provide an alternative model for weight loss due to corrosion of copper in the acid extract of Gnetum Africana. The original three-level factorial design was employed to fit a model describing the weight loss due to corrosion. Equally, a two-level factorial design and Box-Behnken design were alternatively considered for the design constructions, analysis, and modeling the process of the original data. The optimum factor settings for corrosion inhibition were determined to be $24 \mathrm{~h}$, $0.003 \mathrm{~g} / \mathrm{L}$ and $303 \mathrm{~K}$ for time, inhibitor concentration and temperature respectively. It was concluded that the Box-Behnken design was the most efficient, followed by the two-level factorial design, while the three-level factorial design was the least efficient in predicting the weight loss. Indeed, this is a great improvement over the three-level factorial experiment earlier used by Nkuzinna et al. (2014) in relation to resources, time and above all the statistical efficiency, precision and reliability of the model.
\end{abstract}

Keywords: designs of experimental, factorial designs, Box-Behnken design, optimization, corrosion, Gnetum Africana, corrosion inhibition.

Received: July 25, 2019. Published: February 25, 2020

doi: $\underline{10.17675 / 2305-6894-2020-9-1-18}$

\section{Introduction}

Corrosion is the destructive attack of a material by chemical reaction with its environment. Corrosion is an electrochemical reaction, i.e. it comprises both cathodic and anodic half reactions:

Anodic reaction: $\mathrm{Fe}_{(\mathrm{s})} \rightarrow \mathrm{Fe}_{(\mathrm{aq})}^{3+}+3 \mathrm{e}^{-}$

Cathodic reaction: $2 \mathrm{H}_{(\mathrm{aq})}^{+}+2 \mathrm{e}^{-} \rightarrow \mathrm{H}_{2(\mathrm{~g})}$

$$
1 / 2 \mathrm{O}_{2(\mathrm{~g})}+\mathrm{H}_{2} \mathrm{O}_{(1)}+2 \mathrm{e} \rightarrow 2 \mathrm{OH}_{\text {(aq) }}^{-}
$$


The serious consequences of the corrosion process have become a problem of worldwide significance. In addition to our everyday encounters with this form of degradation, corrosion causes plant shutdowns, waste of valuable resources, loss or contamination of product, reduction in efficiency, costly maintenance, and expensive overdesign; it also jeopardizes safety and inhibits technological progress (Roberge, 2000).

Copper and its alloys have good corrosion resistance in water and have excellent heat conductivity, but they corrode easily in acid solutions. They are broadly used in heating systems and condensers. However, these systems should be regularly cleaned due to inlays of carbonates and oxides (which can) diminish their heating transmission. Diluted acids are normally used to clean these surfaces. For preventing of copper corrosion, additives such as inhibitors are generally added to acid (Ravari et al., 2009).

Corrosion inhibitors are defined as chemical substances that, when added in small concentration to an environment, effectively decreases the corrosion rate of metals or alloys (Roberge, 2000). The use of corrosion inhibitors has considerably increased in recent years due to increased awareness of corrosion worldwide. Inhibitors play an important role in controlling corrosion of metals (Quraishi et al., 2001). Various organic and inorganic compound have been used as corrosion inhibitors in aggressive environment, e.g . pyridazine derivatives (Mashuga et al., 2017); quinoxaline derivatives (Olasunkanmi et al., 2016) and selected dyes (Peme et al., 2015). Various Schiffbase (3-acetyl-4hydroxy-6-methyl-(2H)pyran-2-one and 2,2'-(ethylenedioxy)diethylamine) as corrosion inhibitors of mild steel in acidic medium have been reported (Jonnie et al., 2015). Phthalocyanines derivatives containing heteroatoms such as $\mathrm{O}, \mathrm{N}, \mathrm{S}$, and $\mathrm{P}$ are found to have higher basicity and electron donating ability and have also been used as corrosion inhibitors and some ionic liquids (Yesudass et al., 2015).

Broad spectra of organic compounds are available as corrosion inhibitors. Of these, only very few are actually used in practice. This is partly due to the fact that desirable properties of an inhibitor usually extend beyond those simply related to metal protection. Considerations of cost, toxicity, availability and environmental friendliness are of considerable importance (Nkuzinna et al., 2014). Plants are sources of naturally occurring compounds, some with complex molecular structures and having different chemical, biological, and physical properties. The naturally occurring compounds are mostly used because they are environmentally acceptable, cost effective, and have abundant availability. These advantages are the reasons for the use of extracts of plants and their products as corrosion inhibitors for metals and alloys under different environments (Patni et al., 2013). Among natural plants extract as corrosion inhibition of mild steel and aluminum alloy in acidic medium are extracts from Ficus asperifolia (Fadare et al., 2016) and Newbouldia leavis (Lebe et al., 2011). Similarly, the inhibiting effect of Chenopodium extract against the copper corrosion in $1 \mathrm{M} \mathrm{HNO}_{3}$ was studied by weight loss, potentiodynamic polarization, electrochemical impedance spectroscopy (EIS) and electrochemical frequency modulation (EFM) techniques (Motawea, 2019). Inhibitory 
effect of African Pumpkin (Momordica balsamina Linn.) leaf extract on copper corrosion in acidic media was also studied and reported (Maibulangu et al., 2017).

With concerns about the harmful effects of inorganic inhibitors on the environment, several organic corrosion inhibitors have been developed to avoid those problems. The extract of Gnetum Africana is one of such inhibitors. Gnetum Africana (also called African Jointfir) is a forest vine that grows abundantly in Africa, South America, and tropical and subtropical Asia. Its leaves are widely used as an ingredient in soups and stews and they are much in demand for their nutritional and therapeutic properties (Ali et al., 2015). In recent years, the use of Gnetum Africana extract as a corrosion inhibitor has been explored. It has been found to reduce corrosion significantly in carbon, mild steel and stainless steel (Nnanna et al., 2013; Obiukwu et al., 2015; Obiukwu et al., 2016). The phenolic extract has also been shown to inhibit corrosion of copper in ammonium hydroxide (Aliyu and Onyedikachi, 2014). The rate of corrosion of a metal is determined by several factors such as temperature and time. It is therefore imperative to simplify, model and optimize the corrosion inhibition process of Gnetum Africana extract on copper.

In recent time, a full-factorial experiment studying the inhibition effect of acid extract of Gnetum Africana was conducted (Nkuzinna et al., 2014), for the experiment, pure copper sheets (99.9\%) were employed and $\mathrm{HNO}_{3}$ was used to extract the inhibitor from Gnetum Africana leaves. The weight losses due to corrosion were recorded under three different factors (inhibitor concentration, time and temperature), each factor was measured at three levels, making it a 3-level full factorial design with 27 runs.

The study presented a polynomial model describing the process in terms of denoted factors. The regression model having an $R^{2}$ value of 0.8227 is expressed in Equation 1.

$$
\begin{aligned}
& Y_{\text {weight loss }}=2.16-1.04 X_{1}-0.17 X_{1}^{2}+0.33 X_{2}-0.12 X_{2}^{2}-0.64 X_{3}-0.22 X_{3}^{2}+0.27 X_{1} X_{2}+ \\
& 0.13 X_{1}^{2} X_{3}+0.068 X_{1} X_{3}^{2}+0.11 X_{1}^{2} X_{3}^{2}
\end{aligned}
$$

Where $X_{1}, X_{2}$ and $X_{3}$ are time, inhibitor concentration and temperature, respectively and the optimal (minimum) factor settings obtained are $24 \mathrm{~h}, 0.003 \mathrm{~g} / \mathrm{L}$, and $303 \mathrm{~K}$ for time, inhibitor concentration and temperature respectively. Importantly, however, we found that using the statistical model in Equation 1, the predicted weight loss at those settings is $3.30 \mathrm{~g}$, which is much higher than the experimental weight loss value of $0.62 \mathrm{~g}$ in Run $7 \mathrm{of}$ Table 2.

This paper aims to reanalyze the data in order to provide alternative models with better optimal setting as an improvement over the model provided by (Nkuzinna et al., 2014). In addition, to also investigate and identify the most efficient alternative designs (two-level factorial design, three-level factorial design, and Box-Behnken design), in studying the inhibition effect of acid extract of Gnetum Africana on copper corrosion. 


\section{Overview of the original $3^{3}$ factorial experiment}

In 1937, Frank Yates wrote an article titled, the design and analysis of factorial experiments and universally known as "TC35" which designed and analyzed factorial experiments with regard to main and interaction effects was introduced. Factorial designs are frequently used in experiments involving several factors where it is necessary to investigate the joint effect of the factors on a response (Montgomery, 2013). The Doptimal minimax criterion with a suitable tool that minimizes the variance, covariance and bias of the estimations of the optimal fractional factorial split plot designs in which the efficiency was felt when compared with both A- and D-optimal designs was introduced (Saka, et al., 2019).

The three factors considering in this study are time, inhibitor concentration and temperature with their respective levels are presented in Table 1 while Table 2 shows the full experimental runs in a standard form for the original $3^{3}$ factorial design with actual measurements obtained for the factors and the responses.

Table 1. Experimental factors and their respective levels.

\begin{tabular}{cccc}
\hline Factors & Lower limit (-1) & Moderate (0) & Upper limit (+1) \\
\hline Time (h) & 24 & 72 & 120 \\
Inhibitor Concentration (g/L) & 0.001 & 0.002 & 0.003 \\
Temperature (K) & 303 & 318 & 333 \\
\hline
\end{tabular}

Table 2. The $3^{3}$ full factorial design showing runs in standard form and responses.

\begin{tabular}{ccccc}
\hline Runs & Time $\boldsymbol{X}_{\mathbf{1}}(\mathbf{h})$ & Inhibitor concentration $\boldsymbol{X}_{\mathbf{2}}(\mathbf{g} / \mathbf{L})$ & Temperature $\boldsymbol{X}_{\mathbf{3}}(\mathbf{K})$ & Weight loss $(\mathbf{g})$ \\
\hline 1 & 24 & 0.001 & 303 & 0.90 \\
2 & 24 & 0.001 & 318 & 0.96 \\
3 & 24 & 0.001 & 333 & 1.86 \\
4 & 24 & 0.002 & 303 & 0.70 \\
5 & 24 & 0.002 & 318 & 1.09 \\
6 & 24 & 0.002 & 333 & 1.72 \\
7 & 24 & 0.003 & 303 & 0.62 \\
8 & 24 & 0.003 & 318 & 0.85 \\
9 & 24 & 0.003 & 333 & 1.36 \\
10 & 72 & 0.001 & 303 & 1.68 \\
11 & 72 & 0.001 & 318 & 2.02 \\
12 & 72 & 0.001 & 333 & 3.54 \\
\hline
\end{tabular}




\begin{tabular}{ccccc}
\hline Runs & Time $\boldsymbol{X}_{\mathbf{1}}(\mathbf{h})$ & Inhibitor concentration $\boldsymbol{X}_{\mathbf{2}}(\mathbf{g} / \mathbf{L})$ & Temperature $\boldsymbol{X}_{\mathbf{3}}(\mathbf{K})$ & Weight loss $(\mathbf{g})$ \\
\hline 13 & 72 & 0.002 & 303 & 1.40 \\
14 & 72 & 0.002 & 318 & 1.95 \\
15 & 72 & 0.002 & 333 & 1.40 \\
16 & 72 & 0.003 & 303 & 1.32 \\
17 & 72 & 0.003 & 318 & 1.64 \\
18 & 72 & 0.003 & 333 & 2.88 \\
19 & 120 & 0.001 & 303 & 2.84 \\
20 & 120 & 0.001 & 318 & 3.18 \\
21 & 120 & 0.001 & 333 & 5.37 \\
22 & 120 & 0.002 & 303 & 2.18 \\
23 & 120 & 0.002 & 318 & 3.07 \\
24 & 120 & 0.002 & 333 & 4.84 \\
25 & 120 & 0.003 & 303 & 1.96 \\
26 & 120 & 0.003 & 318 & 2.67 \\
27 & 120 & 0.003 & 333 & 4.20 \\
\hline
\end{tabular}

*This is the original data given by Nkuzinna et al., 2014.

\subsection{Results and discussions of the original $3^{3}$ factorial experiment}

Here, the results of the analysis carried out on the dataset presented in Table 2 are discussed.

Table 3. Analysis of variance of original $3^{3}$ factorial experiment.

\begin{tabular}{lccccc}
\hline Source & Sum of squares & DF & Mean square & $\boldsymbol{F}$-value & $\boldsymbol{p}$-values \\
\hline Model & 36.167 & 4 & 9.042 & 46.526 & $<0.0001$ \\
Error & 4.275 & 22 & 0.194 & & \\
Total & 40.442 & 26 & & & \\
\hline
\end{tabular}

Table 4. Parameter estimates of the original $3^{3}$ factorial experiment.

\begin{tabular}{cccc}
\hline Term & Estimate & $\boldsymbol{t}$-value & $\boldsymbol{p}$-values \\
\hline Intercept & 2.1555556 & 25.41 & $<0.0001^{*}$ \\
Time & 1.125 & 10.83 & $<0.0001^{*}$ \\
Conc. & -0.269444 & -2.59 & $0.0166^{*}$ \\
\hline
\end{tabular}




\begin{tabular}{cccc}
\hline Term & Estimate & $\boldsymbol{t}$-value & $\boldsymbol{p}$-values \\
\hline Temp & 0.7538889 & 7.26 & $<0.0001^{*}$ \\
Time*temp & 0.3925 & 3.08 & $0.0054^{*}$ \\
\hline
\end{tabular}

From Table 3, the analysis of variance confirms that there is sufficient evidence to reject the null hypothesis ( $F$-value of 46.53 and a $p$-value of 0.0001 ), meaning that at least one of the model parameters is significant and useful in explaining variability in the weight loss. Also, the coefficient of determination, $R^{2}$, and adjusted $R^{2}$ of the model are 0.894 and 0.875 respectively, which is an indication that an approximately $90 \%$ of the variability in the weight loss is explained or accounted for by the model in Equation 2.

The parameter estimates of the treatment effects: time, temperature, time $\cdot$ temperature and inhibitor concentration that are significant and sensitive to the weight loss due to corrosion are presented in the Table 4 above. This is eventually represented as a model in Equation 2, which is clearly supported by the half normal plot in Figure 1.

$$
Y_{\text {weight loss }}=2.1556+1.125 X_{1}-0.2694 X_{2}+0.7539 X_{3}+0.3925 X_{1} X_{3}
$$

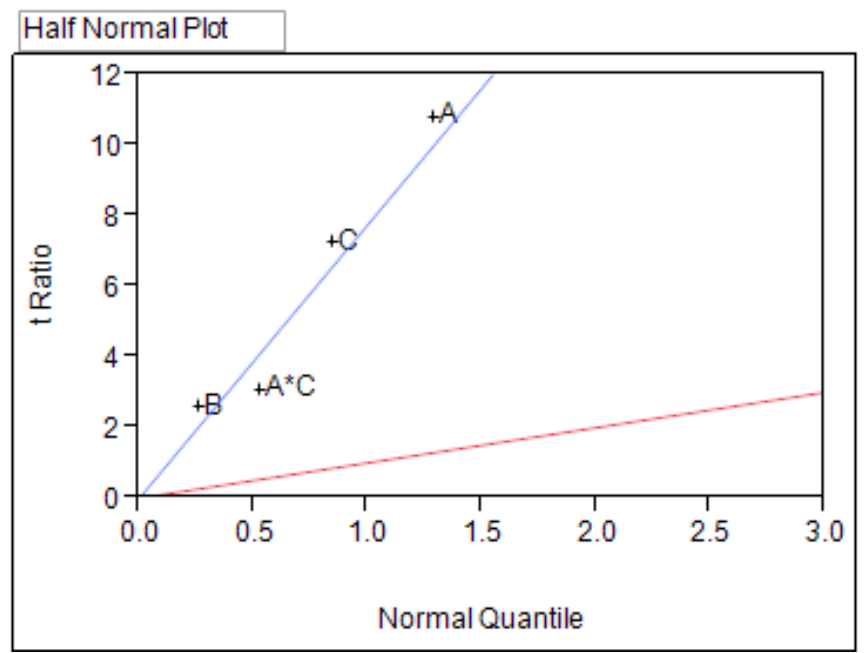

A: Time, B: Inhibitor concentration and C: Temperature

Figure 1. Half-normal plot on $3^{3}$ factorial experiments for the independent variables.

\subsection{Optimal evaluation of $3^{3}$ factorial experiments}

The Figures 2 and 3 are used to evaluate the model obtained in Equation 2 and also to obtain the optimal values. As such, the optimum values of the factors that minimize weight loss due to corrosion are shown in Table 5. 


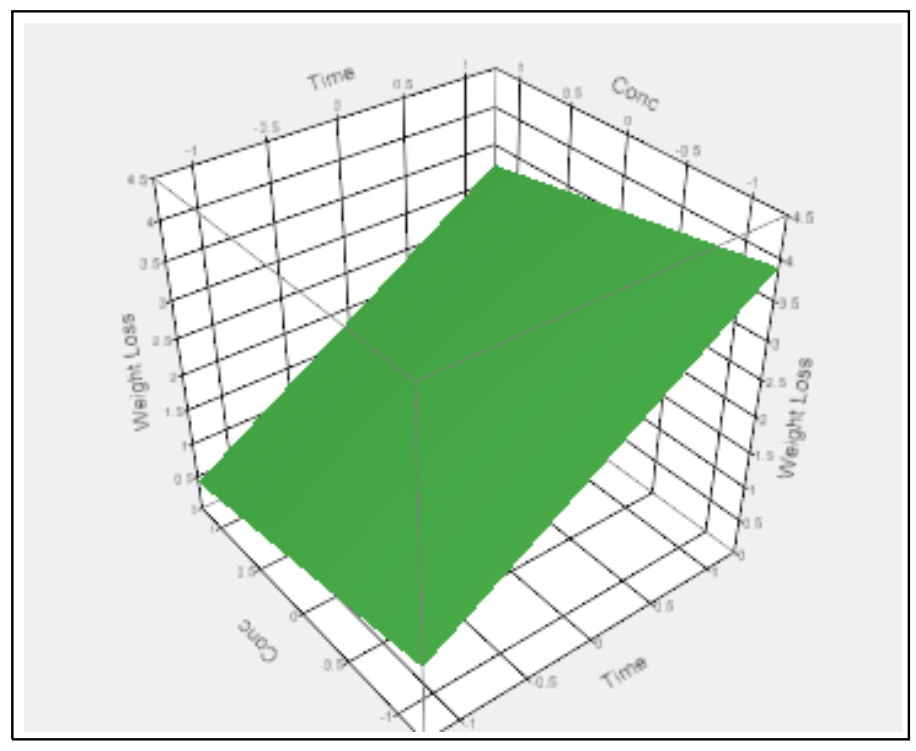

Figure 2. Response surface plot of time against inhibitor concentration.

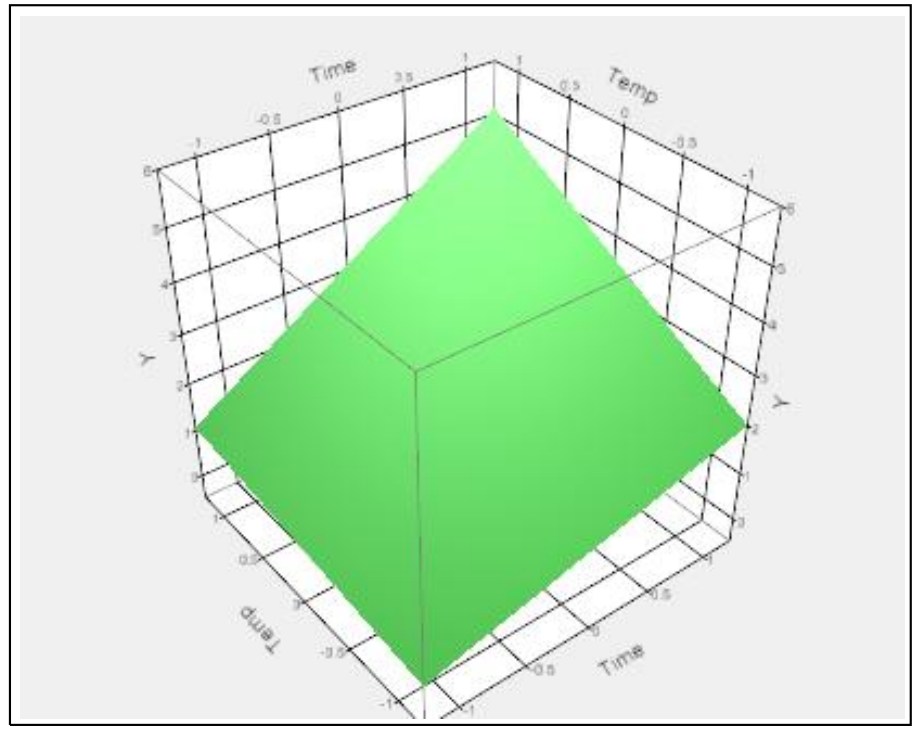

Figure 3. Response surface plot of time against temperature.

Table 5. Optimum values of $3^{3}$ factorial experiments.

\section{Parameters}

Weight loss $(\mathrm{g})$

Time (h)

Inhibitor concentration $(\mathrm{g} / \mathrm{L})$

Temperature $(\mathrm{K})$

\section{Optimum values}

$$
\begin{gathered}
0.400 \\
24 \\
0.003
\end{gathered}
$$$$
303
$$ 


\section{The $2^{3}$ factorial experiment}

Full two-level factorial designs are carried out to determine whether certain main factors or interactions (two or more) factors have effects on the response variable and also to estimate the magnitude of such effects. The designs require an experiment to be carried out on all possible combinations of the two levels of each of the $k$ factors considered.

Here, Table 6 presents the $2^{3}$ factorial experimental runs obtained from the $3^{3}$ factorial experimental dataset in Table 2, in which the levels were measured at either low $(-1)$ or high $(+1)$. This exercise becomes necessary to create an opportunity to compare, identify and recommend the most efficient model that minimizes weight loss due to corrosion among various alternative models.

Table 6. The $2^{3}$ full factorial design showing runs in actual factors and responses.

\begin{tabular}{ccccc}
\hline Runs & Time $\left(\boldsymbol{X}_{\mathbf{1}}, \mathbf{h}\right)$ & $\begin{array}{c}\text { Inhibitor concentration } \\
\left(\boldsymbol{X}_{\mathbf{2}}, \mathbf{g} / \mathbf{L}\right)\end{array}$ & Temperature $\left(\boldsymbol{X}_{\mathbf{3}}, \mathbf{K}\right)$ & Weight loss $(\mathbf{g})$ \\
\hline 1 & 24 & 0.001 & 303 & 0.90 \\
2 & 120 & 0.001 & 303 & 2.84 \\
3 & 24 & 0.003 & 303 & 0.62 \\
4 & 120 & 0.003 & 303 & 1.96 \\
5 & 24 & 0.001 & 333 & 1.86 \\
6 & 120 & 0.001 & 333 & 5.37 \\
7 & 24 & 0.003 & 333 & 1.36 \\
8 & 120 & 0.003 & 333 & 4.20 \\
\hline
\end{tabular}

\subsection{Results and discussion}

Here, the results of the analysis carried out on the dataset presented in Table 6 are discussed.

Table 7. Analysis of variance of $2^{3}$ factorial experiment.

\begin{tabular}{cccccc}
\hline Source & Sum of squares & DF & Mean square & $\boldsymbol{F}$-value & $\boldsymbol{p}$-values \\
\hline Model & 19.004 & 4 & 4.751 & 60.719 & 0.0033 \\
Error & 0.235 & 3 & 0.078 & & \\
Total & 19.239 & 7 & & & \\
\hline
\end{tabular}


Table 8. Parameter estimates for the $2^{3}$ factorial experiment.

\begin{tabular}{cccc}
\hline Term & Estimate & $\boldsymbol{t}$-value & $\boldsymbol{p}$-values \\
\hline Intercept & 2.38875 & 24.15 & $0.0002^{*}$ \\
Time & 1.20375 & 12.17 & $0.0012^{*}$ \\
Conc & -0.35375 & -3.58 & $0.0374^{*}$ \\
Temp & 0.80875 & 8.18 & $0.0038^{*}$ \\
Time·temp & 0.38375 & 3.88 & $0.0303^{*}$ \\
\hline
\end{tabular}

From Table 7, the analysis of variance confirms that there is sufficient evidence to reject the null hypothesis ( $F$-value of 60.719 and a $p$-value of 0.0033 ), meaning that at least one of the model parameters is significant and useful in explaining variability in the weight loss. Also, the coefficient of determination, $R^{2}$, and adjusted $R^{2}$ of the model are 0.988 and 0.972 respectively, which is an indication that an approximately $99 \%$ of the variability in the weight loss is explained or accounted for by the model in Equation 3.

The parameter estimates of the treatment effects: time, temperature, time*temperature and inhibitor concentration that are significant and sensitive to the weight loss due to corrosion are presented in the table 7 above. This is eventually represented as a model in Equation 3, which is clearly supported by the half normal plot in Figure 4.

$$
Y_{\text {weight loss }}=2.3888+1.2038 X_{1}-0.3538 X_{2}+0.8088 X_{3}+0.3838 X_{1} X_{3}
$$

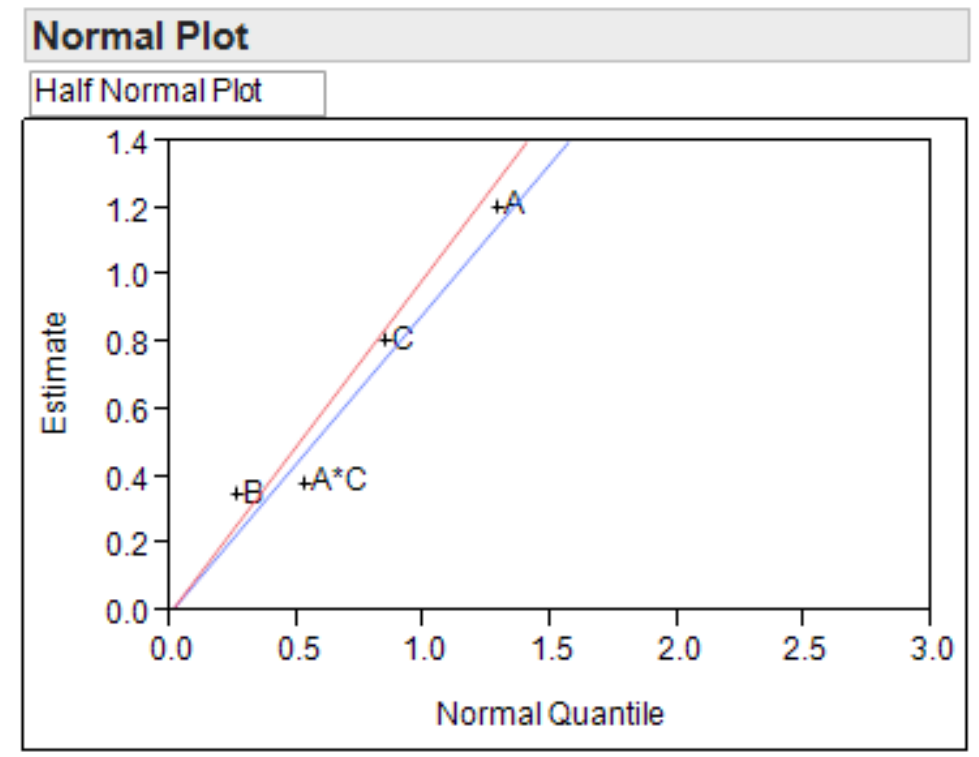

Blue line has slope equal to Lenth's PSE.

Red line has slope 1.

A: Time, B: Inhibitor concentration and C: Temperature

Figure 4. Half-normal plot on $3^{3}$ factorial experiments for the independent variables. 


\subsection{Optimal evaluation of $2^{3}$ factorial experiments}

The Figures 5 and 6 are used to evaluate the model obtained in Equation 3 and also to obtain the optimal values. As such, the optimum values of the factors that minimize weight loss due to corrosion are shown in Table 9.

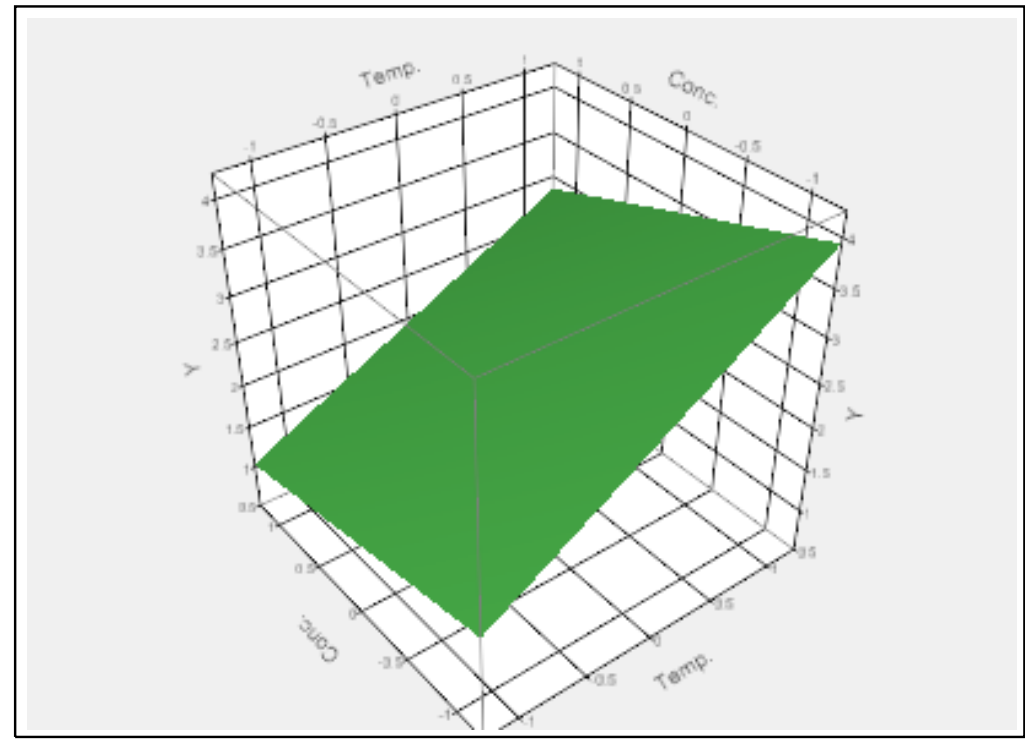

Figure 5. Response surface plot of time against inhibitor concentration.

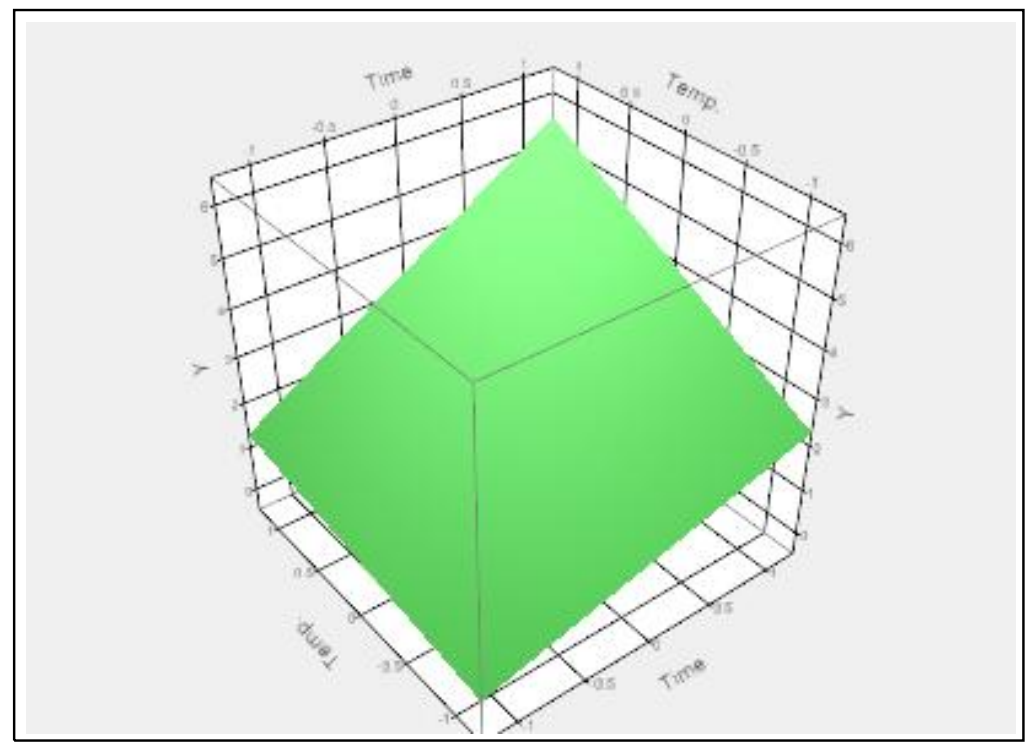

Figure 6. Response surface plot of time against temperature. 
Table 9. Optimum values of $2^{3}$ factorial experiments.

\section{Parameters}

\begin{tabular}{cc}
\hline Weight loss $(\mathrm{g})$ & 0.410 \\
Time $(\mathrm{h})$ & 24 \\
Inhibitor concentration $(\mathrm{g} / \mathrm{L})$ & 0.003 \\
Temperature $(\mathrm{K})$ & 303 \\
\hline
\end{tabular}

\section{The Box-Behnken design (BBD)}

The Box-Behnken was devised by George E. P. Box and Donald Behnken in 1960. It consists of a particular subset of the factorial combinations from the three-level factorial design. A minimum of three control variables can be used, with each variable having three levels (high, medium and low).

Table 10. Data presentation in Box-Behnken design format.

\begin{tabular}{ccccc}
\hline Runs & Time $\left(\mathbf{X}_{\mathbf{1}}, \mathbf{h}\right)$ & $\begin{array}{c}\text { Inhibitor concentration } \\
\left(\boldsymbol{X}_{\mathbf{2}}, \mathbf{g} / \mathbf{L}\right)\end{array}$ & Temperature $\left(\boldsymbol{X}_{\mathbf{3}}, \mathbf{K}\right)$ & Weight loss $(\mathbf{g})$ \\
\hline 1 & 72 & 0.001 & 303 & 1.68 \\
2 & 24 & 0.002 & 303 & 0.7 \\
3 & 120 & 0.002 & 303 & 2.18 \\
4 & 72 & 0.003 & 303 & 1.32 \\
5 & 24 & 0.001 & 318 & 0.96 \\
6 & 120 & 0.001 & 318 & 3.18 \\
7 & 72 & 0.002 & 318 & 1.95 \\
8 & 72 & 0.002 & 318 & $1.95^{*}$ \\
9 & 72 & 0.002 & 318 & $1.95^{*}$ \\
10 & 24 & 0.003 & 318 & 0.85 \\
11 & 120 & 0.003 & 318 & 2.67 \\
12 & 72 & 0.001 & 333 & 3.54 \\
13 & 24 & 0.002 & 333 & 1.72 \\
14 & 120 & 0.002 & 333 & 4.84 \\
15 & 72 & 0.003 & 333 & 2.88 \\
\hline
\end{tabular}

Centre points were repeated* 


\subsection{Results and discussion}

Here, the results of the analysis carried out on the dataset presented in Table 10 are discussed.

Table 11. Analysis of variance of factorial experiment using Box-Behnken design.

\begin{tabular}{cccccc}
\hline Source & Sum of squares & DF & Mean square & $\boldsymbol{F}$-value & $\boldsymbol{p}$-values \\
\hline Model & 17.324 & 5 & 3.465 & 235.692 & $<0.0001$ \\
Error & 0.132 & 9 & 0.014 & & \\
Total & 17.456 & 14 & & & \\
\hline
\end{tabular}

Table 12. Parameter estimates for the Box-Behnken model.

\begin{tabular}{cccc}
\hline Term & Estimate & $\boldsymbol{t}$-value & $\boldsymbol{p}$-values \\
\hline Intercept & 1.93 & 42.12 & $<0.0001^{*}$ \\
Time & 1.08 & 25.19 & $<0.0001^{*}$ \\
Conc. & -0.205 & -4.78 & $0.0010^{*}$ \\
Temp & 0.8875 & 20.70 & $<0.0001^{*}$ \\
Time-temp & 0.41 & 6.76 & $<0.0001^{*}$ \\
Temp.temp & 0.4275 & 6.81 & $<0.0001^{*}$ \\
\hline
\end{tabular}

From Table 11, the analysis of variance confirms that there is sufficient evidence to reject the null hypothesis ( $F$-value of 235.692 and a $p$-value of 0.0001 ), meaning that at least one of the model parameters is significant and useful in explaining variability in the weight loss. Also, the coefficient of determination, $R^{2}$, and adjusted $R^{2}$ of the model are 0.992 and 0.988 respectively, which is an indication that an approximately $99.2 \%$ of the variability in the weight loss is explained or accounted for by the model in Equation 4.

The parameter estimates of the treatment effects: time, temperature, time*temperature and inhibitor concentration that are significant and sensitive to the weight loss due to corrosion are presented in the Table 12 above. This is eventually represented as a model in Equation 4, which is clearly supported by the half normal plot in Figure 7.

$$
Y_{\text {weight loss }}=1.93+1.08 X_{1}-0.205 X_{2}+0.8875 X_{3}+0.41 X_{1} X_{3}+0.4275 X_{3} X_{3}
$$




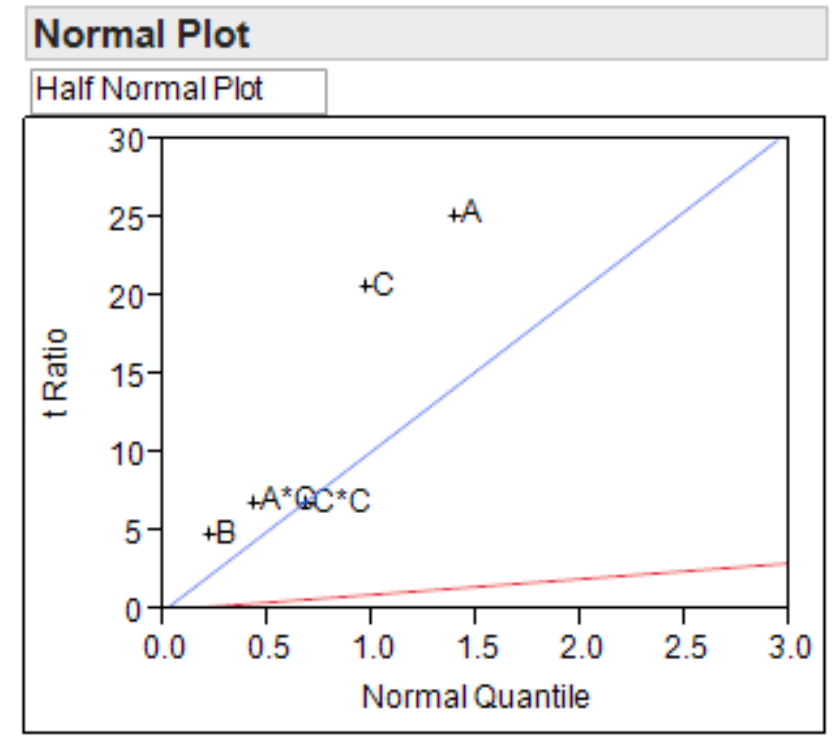

Blue line has slope equal to Lenth's PSE.

Red line has slope 1.

A: Time, B: Inhibitor concentration and C: Temperature

Figure 7. Half-normal plot on Box-Behnken design for the independent variables.

\subsection{Optimal evaluation on Box-Behnken design}

The Figures 8 and 9 are used to evaluate the model obtained in Equation 4 and also to obtain the optimal values. As such, the optimum values of the factors that minimize weight loss due to corrosion are presented in Table 13.

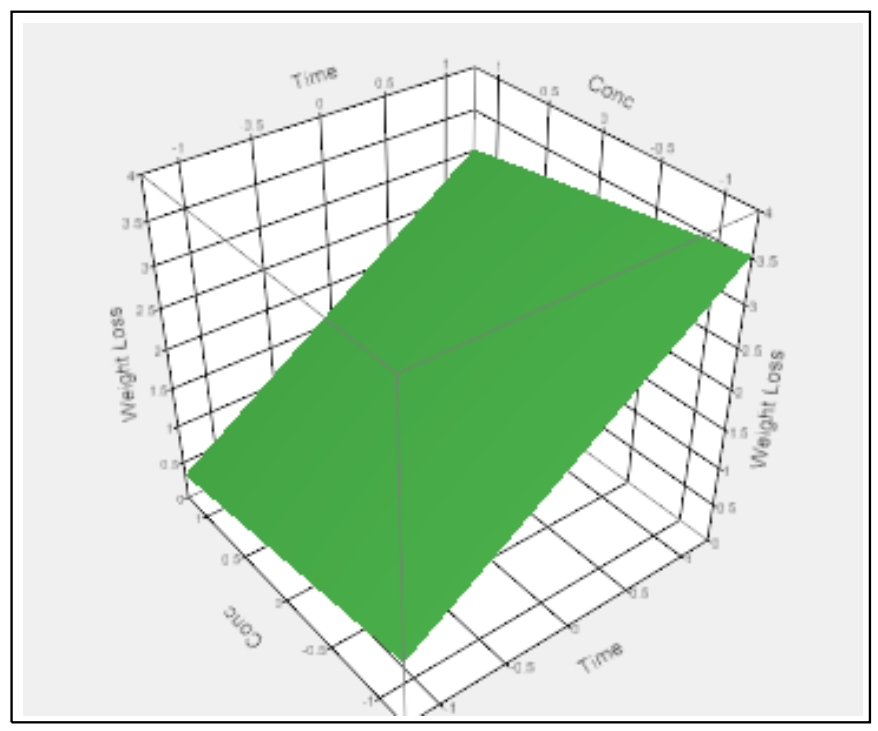

Figure 8. Response surface plot of time against concentration. 


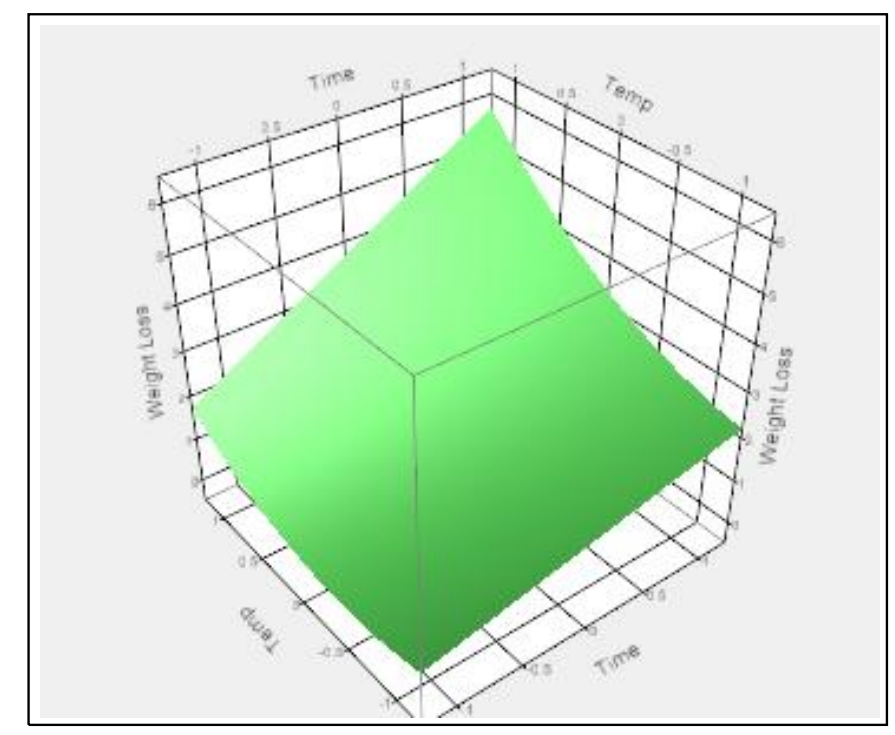

Figure 9. Response surface plot of time against temperature.

Table 13. Optimum values for Box-Behnken model.

\begin{tabular}{cc}
\hline Parameters & Optimum Values \\
\hline Weight loss $(\mathrm{g})$ & 0.600 \\
Time $(\mathrm{h})$ & 24 \\
Inhibitor concentration $(\mathrm{g} / \mathrm{L})$ & 0.003 \\
Temperature $(\mathrm{K})$ & 303 \\
\hline
\end{tabular}

\section{Conclusion}

This paper reanalyzed and presented alternatives models to the work of Nkuzinna et al. (2014) on the inhibition of copper corrosion using acid extract of Gnetum Africana, under three independent factors of time, inhibitor concentration and temperature. Nkuzinna et al. gave the optimal (minimum) factor settings to be $24 \mathrm{~h}, 0.003 \mathrm{~g} / \mathrm{L}$, and $303 \mathrm{~K}$ for time, inhibitor concentration and temperature respectively. However, it was found that using the statistical model in Equation 1, the predicted weight loss at those settings is $3.30 \mathrm{~g}$, which is much higher than the experimental weight loss value of $0.62 \mathrm{~g}$ in Run 7 of Table 2 .

Upon this discovery, this paper explored different factorial tools such as a two-level full-factorial design, a three-level full-factorial design and a Box-Behnken design to construct factorial designs and model inhibition of copper corrosion using acid extract of Gnetum Africana. Results obtained from the analysis in Section 2, 3 and 4 showed that the three-level full-factorial design earlier proposed by Nkuzinna et al. (2014) was relatively less reliable for predicting the effects of the independent factors on the weight loss.

As such, Box-Behnken design gave an efficient model with approximately $99.2 \%$ of the variability in the weight loss being explained or accounted for by the model in 
Equation 4. On a final note, BBD also optimized the process with a minimum number of experimental runs, with an achievement of approximate values of weight loss when compared with other designs in Section 2 and 3 in the realization of the initial experimental dataset.

\section{References}

1. F. Ali, M.A. Assanta and C. Robert, Gnetum africanum: a wild food plant from the African forest with many nutritional and medicinal properties, J. Med. Food, 2015, 14, no. 11, 1289-1297. doi: 10.1089/jmf.2010.0327

2. A.O. Aliyu and E. Onyedikachi, Corrosion inhibition effect of phenolic extract of Gnetum Africana on copper in $1.0 \mathrm{~mol} / \mathrm{dm}^{3}$ ammonium hydroxide, Am. Chem. Sci. J., 2014, 4, no. 6, 952-962. doi: 10.9734/ACSJ/2014/11661

3. D. Behnken, Some new three level designs for the study of quantitative variables, Technometrics, 1960, 455-475.

4. O.O. Fadare, A.E. Okoronkwo and E.F. Olasehinde, Assessment of anti-corrosion potentials of extract of Ficus asperifolia - Miq (Moraceae) on mild steel in acidic medium, Afr. J. Pure Appl. Chem., 2016, 10, 8-22. doi: 10.5897/AJPAC2015.0651

5. A. Lebe, O.C. Nnanna, N.D. Nwadiuko, C.F. Ekekwe, S.C. Ukpabi, K.B. Udensi, B.N.O. Okeoma and M.M. Ihebrodike, Adsorption and inhibitive properties of leaf extract of Newbouldia leavis as a green inhibitor for aluminum alloy in $\mathrm{H}_{2} \mathrm{SO}_{4}, A m$. J. Mater. Sci., 2011, 1, no. 2, 143-148. doi: 10.5923/j.materials.20110102.24

6. B.M. Maibulangu, M.B. Ibrahim and L.K. Akinola, Inhibitory effect of African Pumpkin (Momordica balsamina Linn.) leaf extract on copper corrosion in acidic media, J. Appl. Sci. Environ. Manage., 2017, 21, 1067-1071. doi: 10.4314/jasem.v21i6.12

7. M.E. Mashuga, L.O. Olasunkanmi, A.S. Adekunle, S. Yesudass, M.M. Kabanda and E.E. Ebenso, Adsorption, thermodynamic and quantum chemical studies of 1-hexyl-3methylimidazolium based ionic liquids as corrosion inhibitors for mild steel in $\mathrm{HCl}$, Materials, 2015, 8, 3607-3632. doi: 10.3390/ma8063607

8. D.C. Montgomery, Design and analysis of experiments, $8^{\text {th }}$ edition, 2013, John Wiley and Sons, New York.

9. M.M. Motawea, A. El-Hossiany and A.S. Fouda, Corrosion control of copper in nitric acid solution using chenopodium extract, Int. J. Electrochem. Sci., 2019, 14, 1372 1387. doi: $10.20964 / 2019.02 .29$

10. L. Nnanna, I.O. Owate, O.C. Nwadiuko, N.D. Ekekwe and W.J. Oji, Adsorption and corrosion inhibition of Gnetum Africana leaves extracts on carbon steel, Int. J. Mater. Chem., 2013, 3, no. 1, 10-16. doi: 10.5923/j.ijmc.20130301.03

11. O.C. Nkuzinna, M.C. Menkiti, O.D. Onukwuli, G.O. Mbah, B.I. Okolo, M.C. Egbujor and R.M. Government, Application of factorial design of experiment for optimization of inhibition effect of acid extract of Gnetum Africana on copper corrosion, Nat. Resour., 2014, 5, 299-307. doi: 10.4236/nr.2014.57028 
12. O. Obiukwu, I. Opara and L.U. Grema, Corrosion inhibition of mild steel by various plant extracts in acid media, Res. J. Appl. Sci., Eng. Technol., 2015, 10, no. 10, 11971205. doi: $\underline{10.19026 / \text { rjaset. } 10.1888}$

13. O. Obiukwu, I. Opara and C. Asoluka, The inhibitive effect of Gnetum Africana, Gongronema latifolium and Chromolena odaratum extracts on corrosion of stainless steel in $1 \mathrm{M} \mathrm{HCl}$ and $\mathrm{H}_{2} \mathrm{SO}_{4}$ solutions, Int. Lett. Chem., Phys. Astron., 2016, 66, 2537. doi: 10.18052/www.scipress.com/ILCPA.66.25

14. L.O. Olasunkanmi, M.M. Kabanda and E.E. Ebenso, Quinoxaline derivatives as corrosion inhibitors for mild steel in hydrochloric acid medium: Electrochemical and quantum chemical studies, Phys. E (Amsterdam, Neth.), 2016, 76, 109-126. doi: 10.1016/j.physe.2015.10.005

15. T. Peme, L.O. Olasunkanmi, I. Bahadur, A.S. Adekunle, M.M. Kabanda and E.E. Ebenso, Adsorption and corrosion inhibition studies of some selected dyes as corrosion inhibitors for mild steel in acidic medium: gravimetric, electrochemical, quantum chemical studies and synergistic effect with iodide ions, Molecules, 2015, 20, 16004-16029. doi: 10.3390/molecules200916004

16. N. Patni, S. Agarwal and P. Shah, Greener approach towards corrosion inhibition, Chin. J. Eng., Article ID 784186, 2013. doi: 10.1155/2013/784186

17. M.A. Quraishi, R. Sardar and D. Jamal, Corrosion inhibition of mild steel in hydrochloric acid by some aromatic hydrazides, Mater. Chem. Phys., 2001, 71, 309313. doi: 10.1016/S0254-0584(01)00295-4

18. F.B. Ravari, A. Dadgarinezhad and I. Shekhshoaei, Investigation on two salen type Schiff base compounds as corrosion inhibition of copper in $0.5 \mathrm{M} \mathrm{H}_{2} \mathrm{SO}_{4}$, Gazi Univ. J. Sci., 2009, 22, 175-182.

19. P. Roberge, Handbook of Corrosion Engineering, McGraw-Hill Professional, 2000, vol. 1, 833, ISBN: 0070765162.

20. A.J. Saka, A.A. Olosunde and B.B. Adeoye, D-optimal minimax criterion for Twolevel fractional factorial split plot designs, Advances in mathematics; scientific journal, 2019,8 , no. 2, 103-114.

21. F. Yates, The design and analysis of factorial experiments, Imperial Bureau of soil science, Harpenden, UK, 1937.

22. S. Yesudass, A.S. Adekunle, L.O. Olasunkanmi, I. Bahadur, R. Baskar, M.M. Kabanda, I.B. Obot and E.E. Ebenso, Experimental, quantum chemical and Monte Carlo simulation studies on the corrosion inhibition of some alkyl imidazolium ionic liquids containing tetrafluoroborate anion on mild steel in acidic medium, J. Mol. Liq., 2015, 211, 105-118. doi: 10.1016/j.molliq.2015.06.052 